\title{
Article
}

\section{Pretreatment Ethanol From Cellulosic}

\author{
Endah R Dyartanti ${ }^{1}$, Margono ${ }^{1}$, Ike Puji Lestari ${ }^{1}$, Muhamad Iqbal Putra ${ }^{1}$, and Ulfa Intan Pratiwi ${ }^{1}$ \\ 1 Chemical Engineering, Engineering Faculty, Universitas Sebelas Maret \\ E-mail: endah_rd@staff.uns.ac.id (Corresponding author)
}

\begin{abstract}
Pretreatment is an important tool for practical cellulose conversion processes and can be carried out in different ways such as mechanical pretreatment, steam explosion, ammonia fiber explosion, supercritical CO2 treatment, alkali or acid pretreatment, ozone pretreatment, physicochemical pretreatment, dilute-acid pretreatment and biological pretreatment. Biomass pretreatment with hot water $(\mathrm{HW})$ is the most investigated physicochemical method use the differences in the thermal stabilities of the major components of lignocellulosic materials. Acid pretreatment of lignocellulosic biomass aims at increasing the sugar substrate digestibility, defined as the concentration of reducing sugars after the hydrolysis, by microorganisms. Acid hydrolysis is an attractive pretreatment method as the hemicellulose degradation runs with the efficiency of approximately $20-90 \%$, depending on the process conditions. Dilute acid (DA) processes with continued research and development, no significant breakthroughs have been made to raise the glucose yields much higher than $65-70 \%$. Acid pretreatment is much more effective than water and alkaline pretreatment in terms of cellulose accessibility increase compared with DA and HW pretreatment.
\end{abstract}

Keywords: ethanol, cellulosic, pretreatment

EQUILIBRIUM Volume 3 No.1 July 2019

Online at http:/ / equilibrium.ft.uns.ac.id 



\section{Introduction}

Lignocellulose, being the most abundant, cheapest, and easiest grown form of biomass, is an interesting feedstock for the production of biofuels and valuable chemical compounds. Lignocellulose is a basic component of plants and is widely exploited by various branches of industry, e.g., pharmaceutical, food and cosmetic industries. Lignocellulose is a widely available material that cannot be consumed as food by people or animal. It is proposed that high-value by-products and gas-liquid-solid pyrolysis products should be improved in terms of pretreatment processes instead of the chemical reaction rates [1]

The physical form and size of the lignocellulose material structure determines the pretreatment methods that should potentially be used, including any necessary high energy-need mechanical pretreatment [2]. A potential solution is to develop second-generation biofuels and biobased products that utilize nonfood plant materials. Lignocellulose is composed of three main fractions: cellulose (30-60\% of dry matter), hemicellulose (14-40\% of dry matter), and lignin (7-25\% of dry matter). The relative abundance of cellulose, hemicellulose, and lignin are the factors for potential energy productivity.

Cellulose is an unbranched crystalline structured biopolymer composing the cell walls of plants as well as bacteria, fungi, and algae. Cellulose is composed of several to hundreds of thousands of units of glucose, connected by $\beta-1,4$-glicosidic bonds [1]. Hemicellulose is a branched heteropolymer composed of hexoses (D-galactose, L-galactose, D-mannose, L-fructose), pentoses (L-rhamnose, arabinose, xylose), D-glucuronic acid and acetylated sugars [2]. Lignin is an amorphous, water-insoluble heteropolymer. Lignin is a product of condensation of three monomeric phenol alcohols: trans-p-cumarylic, trans-p-coniferylic, trans-p-sinapylic. Lignin is a component of a cell wall and its main biological function is to form an impermeable structure that protects a plant from an invasion of microbes [3][4]. To make the conversion, these raw materials must be subjected to pretreatments which open the structure of the biomass and allow easier release of fermentable monosaccharide. Three main factors facilitate the release of fermentable sugars [5]. The first factor includes the separation of hemicelluloses, which increases the accessibility of the cellulose fraction by creation of large pores in the fiber structure, resulting in an increase of the number of sites available for hydrolysis reactions [6]. The second factor is the crystallinity of the cellulose. Various studies show that thermochemical treatments tend to increase the crystallinity index of the cellulose fraction, resulting in a decrease of the accessibility of the substrate. Finally, the accessibility to the cellulose fibers is strongly limited by the presence of the lignin matrix, surrounding the cellulose fraction. Lignin removal is essential for the achievement of efficient (enzymatic or chemical) hydrolysis [7].

The biggest limitation regarding exploitation of lignocellulose as a substrate for biohydrogen production via fermentation method is the problem of efficient lignocellulose hydrolysis to sugars in biohydrogen production. The main aims of the pretreatment include the disintegration of a tight towards the cellulose. During hydrolysis, as a result of chemical and biochemical processes catalyzed by enzymes, together with physical and physicochemical treatment, a decomposition of organic matter occurs [8].

The resulting simple chemical compounds are metabolized by microorganisms during the fermentation processes. The increase of biohydrogen production efficiency requires the development of economically and environmentally friendly technologies for lignocellulosic biomass pretreatment [9].

\section{Discussion}

Processing of lignocellulosics to bioethanol consists of four major unit operations: pretreatment, hydrolysis, fermentation and product separation/distillation[10]. Schematic flowsheet for the bioconversion of biomass to bioethanol is shown in Fig. 1. The first step in the conversion of biomass to ethanol is size reduction and pretreatment. The goal of any pretreatment technology is to alter or remove structural and compositional impediments to hydrolysis in order to improve the rate of enzyme hydrolysis and increase yields of fermentable sugars from cellulose or hemicellulose [11]. A successful pretreatment must meet the following requirements [12][13]: (i) improve formation of sugars or the ability to subsequently form sugars by hydrolysis, (ii) avoid degradation or loss of carbohydrate, (iii) avoid formation of byproducts inhibitory to subsequent hydrolysis and fermentation processes, and (iv) be cost effective.

The hemicellulose and cellulose polymers are hydrolyzed with enzymes or acids to release monomeric sugars. The sugars from the pretreatment and enzymatic hydrolysis steps are fermented by bacteria, yeast or filamentous fungi, although the enzymatic hydrolysis and fermentation can also be performed in a combined step - a so-called simultaneous saccharification and fermentation (SSF) [14]. 


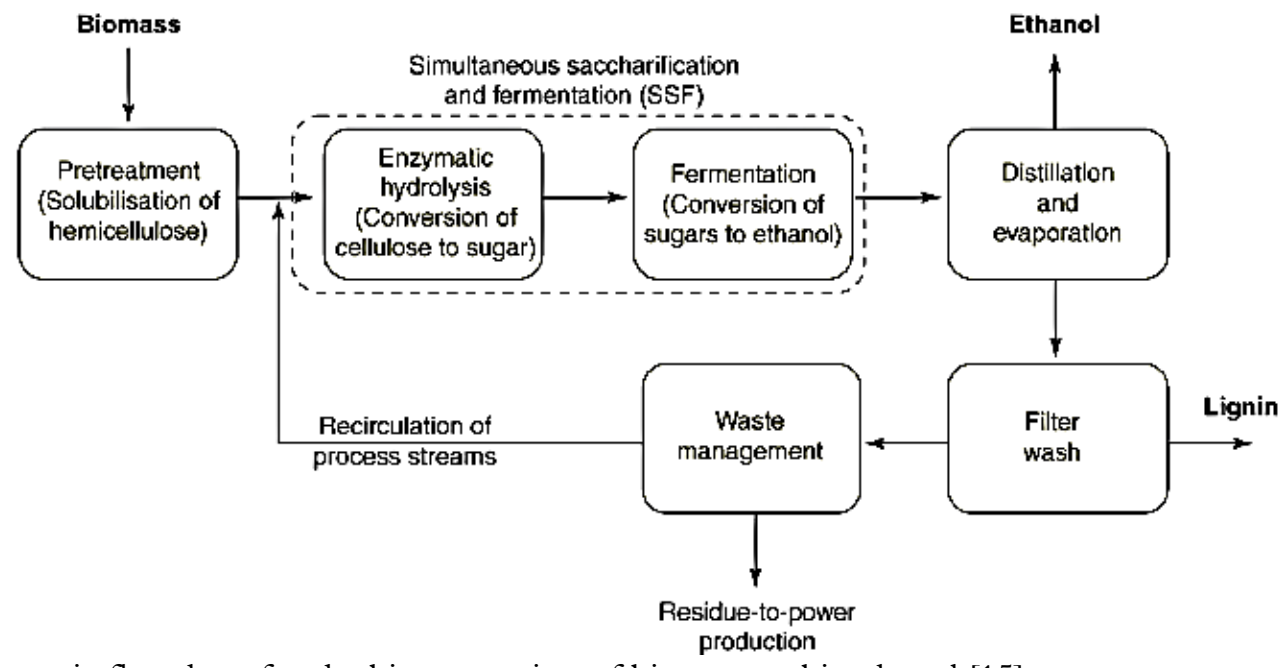

Fig. 1 Schematic flowsheet for the bioconversion of biomass to bioethanol [15]

Pretreatment is an important tool for practical cellulose conversion processes shown in Fig. 2. Cellulose is a long chain of glucose molecules, linked to one another primarily by glycosidic bonds; hemicelluloses is not a chemically well-defined compound but rather a family of polysaccharides that links cellulose fibers into microfibrils and cross-links with lignin, creating a complex network of bonds that provide structural strength; and lignin, a three-dimensional polymer of phenylpropanoid units, is considered to be the cellular glue, providing the plant tissue and the individual fibers with compressive strength and the cell wall with stiffness (Fig. 3) [16].

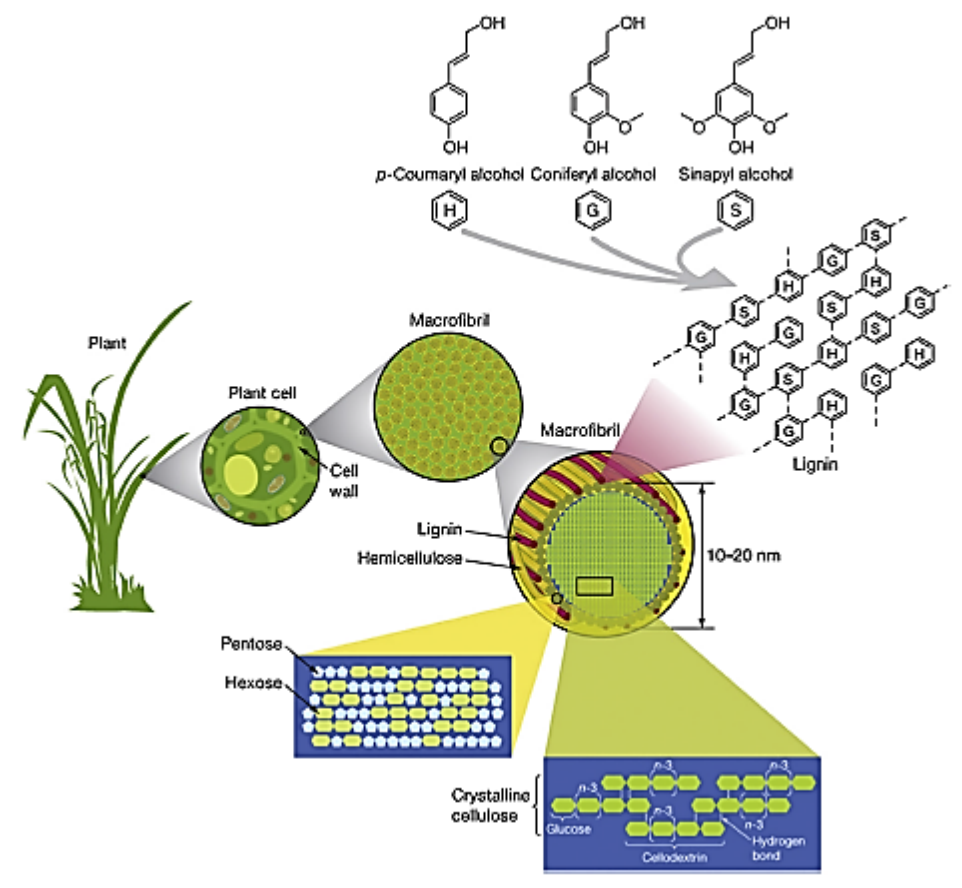

Fig. 2 Structure of lignocellulosic biomass [16]

Pretreatment is required to alter the structure of cellulosic biomass to make more accessible to the enzymes that convert the carbohydrate polymers into fermentable sugars and to cellulose producing microorganisms shown in Fig. 3 [1,2]. 


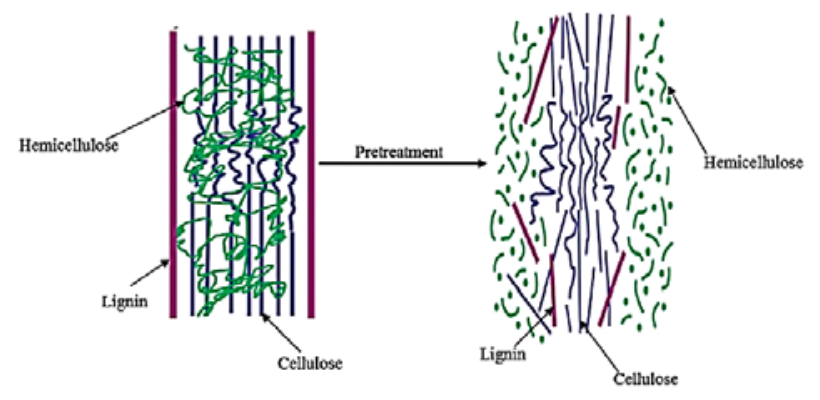

Fig. 3 The role of pretreatment on the recalcitrant structure of lignocellulosic biomass [17]

Pretreatment can be carried out in different ways such as mechanical pretreatment, steam explosion, ammonia fiber explosion, supercritical CO2 treatment, alkali or acid pretreatment, ozone pretreatment, physicochemical pretreatment, dilute-acid pretreatment and biological pretreatment [18].

\subsection{Steam explosion / Physicochemical pretreatment}

Physicochemical methods enable the decomposition of the lignocellulose structure by means of oxidation combined with thermal treatment. Physicochemical pretreatment of of lignocellulosic biomass [1]: Biomass pretreatment with hot water, Pretreatment with carbon dioxide, Biomass pretreatment with ammonia

Biomass pretreatment with hot water $(\mathrm{HW})$, wet air oxidation together with/or steam explosion exclusively is the most investigated physicochemical method of biomass pretreatment. These methods use the differences in the thermal stabilities of the major components of lignocellulosic materials. If pretreatment temperature reaches $240^{\circ} \mathrm{C}$, the cellulose was partially degraded, and the crystallinity of the cellulose is reduced. The fragmented lignocellulosic material is exposed to saturated steam at $160-240^{\circ} \mathrm{C}$ under the pressure of 0.7-4.8 MPa. As a result, dissolved hemicellulose and lignin are transferred to the liquid phase, while cellulose remains as a solid. Hemicellulose hydrolysis releases glucose and xylose, which is called autohydrolysis [19][20]. Xiao et al. pretreated bamboo residues with hot water at $140-200^{\circ} \mathrm{C}$ for different times (10-120 min). The degradation efficiency of lignin showed a slight increase with the increase in temperature and time. However, a significant amount of lignin remained in the residues after the hydrothermal pretreatment. The content of lignin (acid-soluble lignin and acid-insoluble lignin) in the residues increased from 25.9 - 41.1\% with the increase of temperature and reaction time [21]. The cellulose and hemicelluloses in the biomass might be partially converted into pseudo-lignin, which resulted in the increase of acid-insoluble lignin [22].

The biomass pretreatment mechanism using carbon dioxide explosion is related to steam explosion [23]. Carbon dioxide explosion uses supercritical $\mathrm{CO}_{2}\left(\mathrm{SC}-\mathrm{CO}_{2}\right)$ to support the biomass digestibility. SC- $\mathrm{CO}_{2}$ or high-pressure $\mathrm{CO}_{2}$ (up to $28 \mathrm{MPa}$ ) is supplied to the biomass placed in a high-pressure vessel [24,25]. Furthermore, it is supposed that carbonic acid is produced from $\mathrm{CO}_{2}$ dissolution in water. Carbonic acid enhances the rate of hydrolysis, especially hemicellulose hydrolysis [23,24]. Pretreatment with carbon dioxide increases the efficiency of cellulose hydrolysis to glucose by approximately $70 \%$ compared to the untreated biomass [25].

The most popular biomass pretreatment with ammonia methods are AFEX and ARP (Ammonia Recovery Process). The AFEX method consists of forming a biomass suspension in anhydrous ammonia at $60-90{ }^{\circ} \mathrm{C}$ with pressure above $3 \mathrm{MPa}$. As a result, the ammonia undergoes fast evaporation and the system cools down. The pressure variations cause swelling of the cellulose and increases its specific area. During the ARP, the ammonia solution percolates through the packed bed,at temperature $\left(150-180^{\circ} \mathrm{C}\right)$ and the solution is recycled or recovered.[26] Moreover, minimalization of fermentation inhibitors formation results from mild process conditions. Ammonia is highly efficient enabling up to $70-85 \%$ delignification of corn straw and approximately $40-60 \%$ removal of hemicelluloses. However, pretreatment with ammonia is not efficient for biomass with high lignin content. [27]. Additionally, the poisonous ammonia fumes generated during process realization causes safety and environmental concerns.

Dilute acid (DA) / Acid pretreatment 
Acid pretreatment of lignocellulosic biomass aims at increasing the sugar substrate digestibility, defined as the concentration of reducing sugars after the hydrolysis, by microorganisms. Acid hydrolysis consists of damaging the lignin structure, dissolution of the hemicellulose and aiding the decomposition of cellulose to simple sugars. Efficient acid hydrolysis must be realized at an increased temperature. Acid hydrolysis is an attractive pretreatment method as the hemicellulose degradation runs with the efficiency of approximately $20-90 \%$, depending on the process conditions. Koostra et al. investigated the hydrolysis of wheat straw using sulfuric, fumaric and maleic acids at a concentration equal to $10 \%$ at temperature of 130,150 , and $170{ }^{\circ} \mathrm{C}$ for $30 \mathrm{~min}$ and under a maximum pressure of $200 \mathrm{Ba}$. [28]. Acid pretreatment is much more effective than water and alkaline pretreatment in terms of cellulose accessibility increase. Further investigation suggests that lignin does not dictate cellulose accessibility to the extent that hemicellulose does, but it does restrict xylan accessibility which in turn controls the access of cellulase to cellulose. [29].

The chemical composition of each of the substrates was determined by the Klason protocol according to TAPPI standard method T-222. The majority of the hemicellulose (98\%), typically characterized by xylan is removed within 10 min of DA pretreatment. The DA and HW pretreatment is ineffective at removal of lignin, and in fact the Klason lignin content actually increases after pretreatment due to the formation of pseudo-lignin. On the other hand, 35\% of lignin can be removed via $60 \mathrm{~min} \mathrm{NaOH}$ pretreatment at $120^{\circ} \mathrm{C}$ while only $28 \%$ of xylan is degraded. Severe DA pretreatment resulted in the highest glucose yield as compared to other pretreatments. And approximately $500 \mathrm{mg}$ of glucose per gram of dry pretreated biomass could be released after $60 \mathrm{~min} 160 \mathrm{oC}$ DA pretreatment. Under the same pretreatment conditions $(120 \mathrm{oC}, 10$ min). alkali pretreated Populus actually has the highest glucose release, approximately $320 \mathrm{mg} \mathrm{g}-1$ of dry biomass.

However, effectiveness of different types of pretreatment methods cannot be simply juged solely on this common basis. Delignification through alkaline-based pretreatment is found to be less effective that removal of hemicelluloses using an acid in terms of cellulose accessibility increase. Lignin also plays a negative role in the processes of enzymatic hydrolysis by binding to cellulases, and this negative effect of lignin could be compensated by the positive effect of cellulose accessibility, especially under severe DA pretreatment conditions.

Dilute acid processes were industrialized in the early part of the 20th century, and even with continued research and development, no significant breakthroughs have been made to raise the glucose yields much higher than $65-70 \%$ [30]. There have been several improvements to the kinetic model originally suggested by Saeman, in which he proposed a hydrolysis sequence cellulose $\rightarrow$ glucose $\rightarrow$ degradation products [31].

However, these more recent models substantiate the results whereby it was predicted that glucose yields higher than $65-70 \%$ are not attainable using dilute sulfuric acid. Conner et al. suggested that once glucose is formed under reaction conditions, it can derivative and/or degrade at a significant rate [32]. Bouchard et al. suggested that only about $60-70 \%$ of the theoretical glucose yield from cellulose can be obtained using a plugflow reactor because the cellulose is chemically altered after about $70 \%$ conversion [33].

Therefore, the resulting solid substrate is not quantitated as cellulose and can no longer be hydrolyzed to release glucose. Mok and Antal suggested that when using a percolation reactor, about $30 \%$ of the hydrolyzed cellulose gives rise to oligomers, which cannot be converted to glucose either at reaction temperature or after traditional post hydrolysis conditions using 4\% sulfuric acid. The dilute-acid-catalyzed rates of cellulose hydrolysis using a flowing reactor were greatly enhanced over those using batch reactor [34].

\subsection{Enzym Hydrolysis}

Enzymes are naturally occurring plant proteins that cause certain chemical reactions to occur. There are two technological developments: enzymatic and direct microbial conversion methods [35]. Enzymatic hydrolysis of natural lignocellulosic materials is a very slow process because cellulose hydrolysis is hindered by structural parameters of the substrate, such as lignin and hemicellulose content, surface area, and cellulose crystallinity [36][37].

Enzymatic hydrolysis of native lignocellulose usually results in solubilization of V20\% of the originally present glucan, some form of pretreatment to increase amenability to enzymatic hydrolysis is included in most process concepts for biological conversion of lignocellulose [38]. Pretreatment, under appropriate conditions, retains nearly all of the cellulose present in the original material and allows close to theoretical yields upon enzymatic hydrolysis[39]. 
During the enzymatic hydrolysis of cellulosic substrates, several factors restrict the sustained catalytic activity of the cellulase mixture. It has been suggested that these limitations are owing to both substrate- and enzyme-related factors and difficult to evaluate the reuse and/or recycle of cellulases, primarily because our current knowledge of the characteristics of cellulase adsorption onto lignocellulosic substrates is insufficient [40].

Generally, enzymatic cellulose degradation is characterized by a rapid initial phase followed by a slow secondary phase that may last until all substrate is consumed. This has been explained most often by the rapid hydrolysis of the readily accessible fraction of cellulose, strong product inhibition, and slow inactivation of absorbed enzyme molecules [41].

Both bacteria and fungi can produce cellulases for the hydrolysis of lignocellulosic materials. These microorganisms can be aerobic or anaerobic, mesophilic or thermophilic. Bacteria belonging to clostridium, cellulomonas, bacillus, thermomonospora, ruminococcus, bacteriodes, erwinia, acetovibrio, microbispora, and Streptomyces can produce cellulases [42].

The widely accepted mechanism for enzymatic cellulose hydrolysis involves synergistic actions by endoglucanses or endo-1,4- $\beta$-glucanases (EG), exoglucanases or cellobiohydrolases (CBH), and $\beta$-glucosidases (BGL)[43] . EG play an important role in the cellulose hydrolysis by cleaving cellulose chains randomly and thus encouraging strong degradation, accessible intramolecular $\beta$-1,4-glucosidic bonds of cellulose chains randomly to produce new chain ends; exoglucanases processively cleave cellulose chains at the ends to release soluble cellobiose or glucose; and BGL hydrolyze cellobiose to glucose in order to eliminate cellobiose inhibition. BGL complete the hydrolysis process by catalyzing the hydrolysis of cellobiose to glucose [44]. Filamentous fungi are the major source of cellulases and hemicellulases. Wild type and mutant strains of Trichoderma sp. (T. viride, T. reesei, T. longibrachiatum) have long been considered to be the most productive and powerful destroyers of crystalline cellulose. CBH I and CBH II are the major T. reesei enzymes, the content of CBH I comprises up to $60 \%$ of the total cellulolytic protein; whereas, the content of CBH II is about $20 \%$ [45].

Similarly, EG I and EG II are the dominant endoglucanases in T. reesei, and presumably act as important partners to CBH I in nature. Such protein yields are comparable or exceed the respective parameters for the best Trichoderma sp. strains (35-40 g/L) [46].

\section{Conclusion}

Pretreatment is known to make biomass more reactive to cellulose by altering the chemical compositions as well as physical structures of biomass.

Biomass pretreatment with hot water (HW), wet air oxidation together with/or steam explosion exclusively is the most investigated physicochemical method use the differences in the thermal stabilities of the major components of lignocellulosic materials. Acid pretreatment of lignocellulosic biomass aims at increasing the sugar substrate digestibility, defined as the concentration of reducing sugars after the hydrolysis, by microorganisms. However, this process is significantly hindered by innate biomass recalcitrance which refers to the characteristics of the lignocellulose to protect its carbohydrates from degradation by cellulases. Dilute acid (DA) processes with continued research and development, no significant breakthroughs have been made to raise the glucose yields much higher than $65-70 \%$. Severe DA pretreatment resulted in the highest glucose yield as compared to other pretreatments. The DA and HW pretreatment is ineffective at removal of lignin, and in fact the klason-lignin content actually increases after pretreatment due to the formation of pseudolignin. Acid pretreatment is much more effective than water and alkaline pretreatment in terms of cellulose accessibility increase. Further investigation suggests that lignin does not dictate cellulose accessibility to the extent that hemicellulose does, but it does restrict xylan accessibility which in turn controls the access of cellulase to cellulose.

\section{References}

[1] K. Wang, J. Chen, S.-N. Sun, R.-C. Sun, Steam explosion, in: Pretreat. Biomass, Elsevier, 2015: pp. 75-104.

[2] M. Balat, H. Balat, C. Öz, Progress in bioethanol processing, Prog. Energy Combust. Sci. 34 (2008) 551-573.

[3] X. Peng, S. Nie, X. Li, X. Huang, Q. Li, Characteristics of the water-and alkali-soluble hemicelluloses 
fractionated by sequential acidification and graded-ethanol from sweet maize stems, Molecules. 24 (2019) 212.

[4] X. Zhou, H. Zhang, Y. Xu, Biodegradation and Utilization of Hemicellulose, in: Funct. Carbohydrates, CRC Press, 2017: pp. 183-218.

[5] N. Jacquet, G. Maniet, C. Vanderghem, F. Delvigne, A. Richel, Application of steam explosion as pretreatment on lignocellulosic material: a review, Ind. Eng. Chem. Res. 54 (2015) 2593-2598.

[6] P. V Neves, A.P. Pitarelo, L.P. Ramos, Production of cellulosic ethanol from sugarcane bagasse by steam explosion: Effect of extractives content, acid catalysis and different fermentation technologies, Bioresour. Technol. 208 (2016) 184-194.

[7] H. Chen, X. Fu, Industrial technologies for bioethanol production from lignocellulosic biomass, Renew. Sustain. Energy Rev. 57 (2016) 468-478.

[8] D.B. Levin, C.R. Carere, N. Cicek, R. Sparling, Challenges for biohydrogen production via direct lignocellulose fermentation, Int. J. Hydrogen Energy. 34 (2009) 7390-7403.

[9] G. Kumar, P. Sivagurunathan, B. Sen, A. Mudhoo, G. Davila-Vazquez, G. Wang, S.-H. Kim, Research and development perspectives of lignocellulose-based biohydrogen production, Int. Biodeterior. Biodegradation. 119 (2017) 225-238.

[10] D. Styarini, Y. Aristiawan, F. Aulia, H. Abimanyu, Y. Sudiyani, Determination of organic impurities in lignocellulosic bioethanol product by GC-FID, Energy Procedia. 32 (2013) 153-159.

[11] L. Montague, A. Slayton, J. Lukas, Lignocellulosic biomass to ethanol process design and economics utilizing co-current dilute acid prehydrolysis and enzymatic hydrolysis for corn stover, Citeseer, 2002.

[12] M. Takagi, A method for production of alcohol directly from cellulose using cellulase and yeast, Chem. Microb. Protein. (1977).

[13] S. Mohapatra, C. Mishra, S.S. Behera, H. Thatoi, Application of pretreatment, fermentation and molecular techniques for enhancing bioethanol production from grass biomass-A review, Renew. Sustain. Energy Rev. 78 (2017) 1007-1032.

[14] X. Jia, X. Peng, Y. Liu, Y. Han, Conversion of cellulose and hemicellulose of biomass simultaneously to acetoin by thermophilic simultaneous saccharification and fermentation, Biotechnol. Biofuels. 10 (2017) 232.

[15] B. Hahn-Hägerdal, M. Galbe, M.-F. Gorwa-Grauslund, G. Lidén, G. Zacchi, Bio-ethanol-the fuel of tomorrow from the residues of today, Trends Biotechnol. 24 (2006) 549-556.

[16] E.M. Rubin, Genomics of cellulosic biofuels, Nature. 454 (2008) 841-845.

[17] P. Kumar, D.M. Barrett, M.J. Delwiche, P. Stroeve, Methods for pretreatment of lignocellulosic biomass for efficient hydrolysis and biofuel production, Ind. Eng. Chem. Res. 48 (2009) 3713-3729.

[18] S.H. Mood, A.H. Golfeshan, M. Tabatabaei, G.S. Jouzani, G.H. Najafi, M. Gholami, M. Ardjmand, Lignocellulosic biomass to bioethanol, a comprehensive review with a focus on pretreatment, Renew. Sustain. Energy Rev. 27 (2013) 77-93.

[19] J.D. McMillan, Pretreatment of lignocellulosic biomass, in: ACS Publications, 1994.

[20] S.S. Tan, D.Y. Li, Z.Q. Jiang, Y.P. Zhu, B. Shi, L.T. Li, Production of xylobiose from the autohydrolysis explosion liquor of corncob using Thermotoga maritima xylanase B (XynB) immobilized on nickel-chelated Eupergit C, Bioresour. Technol. 99 (2008) 200-204.

[21] X. Xiao, J. Bian, M.-F. Li, H. Xu, B. Xiao, R.-C. Sun, Enhanced enzymatic hydrolysis of bamboo (Dendrocalamus giganteus Munro) culm by hydrothermal pretreatment, Bioresour. Technol. 159 (2014) 41-47.

[22] R. Kumar, F. Hu, P. Sannigrahi, S. Jung, A.J. Ragauskas, C.E. Wyman, Carbohydrate derived-pseudolignin can retard cellulose biological conversion, Biotechnol. Bioeng. 110 (2013) 737-753.

[23] Y. Sun, J. Cheng, Hydrolysis of lignocellulosic materials for ethanol production: a review, Bioresour. Technol. 83 (2002) 1-11.

[24] Y.-S. Cheng, Y. Zheng, C.W. Yu, T.M. Dooley, B.M. Jenkins, J.S. VanderGheynst, Evaluation of high solids alkaline pretreatment of rice straw, Appl. Biochem. Biotechnol. 162 (2010) 1768-1784.

[25] A. Hendriks, G. Zeeman, Pretreatments to enhance the digestibility of lignocellulosic biomass, Bioresour. Technol. 100 (2009) 10-18.

[26] H. Jung, H.G. Yoon, W. Park, C. Choi, D.B. Wilson, D.H. Shin, Y.J. Kim, Effect of sodium hydroxide treatment of bacterial cellulose on cellulase activity, Cellulose. 15 (2008) 465.

[27] S. Zhou, L.O. Ingram, Synergistic hydrolysis of carboxymethyl cellulose and acid-swollen cellulose by two endoglucanases (celz and cely) fromerwinia chrysanthemi, J. Bacteriol. 182 (2000) 5676-5682. 
[28] A.M.J. Kootstra, H.H. Beeftink, E.L. Scott, J.P.M. Sanders, Comparison of dilute mineral and organic acid pretreatment for enzymatic hydrolysis of wheat straw, Biochem. Eng. J. 46 (2009) 126-131.

[29] X. Meng, A.J. Ragauskas, Recent advances in understanding the role of cellulose accessibility in enzymatic hydrolysis of lignocellulosic substrates, Curr. Opin. Biotechnol. 27 (2014) 150-158.

[30] R.W. Torget, J.S. Kim, Y.Y. Lee, Fundamental aspects of dilute acid hydrolysis/fractionation kinetics of hardwood carbohydrates. 1. Cellulose hydrolysis, Ind. Eng. Chem. Res. 39 (2000) 2817-2825.

[31] J.F. Saeman, Kinetics of wood saccharification-hydrolysis of cellulose and decomposition of sugars in dilute acid at high temperature, Ind. Eng. Chem. 37 (1945) 43-52.

[32] A.H. Conner, B.F. Wood, C.G. Hill Jr, J.F. Harris, Kinetic model for the dilute sulfuric acid saccharification of lignocellulose, J. Wood Chem. Technol. 5 (1985) 461-489.

[33] J. Bouchard, G. Garnier, P. Vidal, E. Chornet, R.P. Overend, Characterization of depolymerized cellulosic residues, Wood Sci. Technol. 24 (1990) 159-169.

[34] W.S. Mok, M.J. Antal Jr, G. Varhegyi, Productive and parasitic pathways in dilute acid-catalyzed hydrolysis of cellulose, Ind. Eng. Chem. Res. 31 (1992) 94-100.

[35] A. Demirbaş, Ethanol from cellulosic biomass resources, Int. J. Green Energy. 1 (2004) 79-87.

[36] S.D. Mansfield, C. Mooney, J.N. Saddler, Substrate and enzyme characteristics that limit cellulose hydrolysis, Biotechnol. Prog. 15 (1999) 804-816.

[37] P. Alvira, E. Tomás-Pejó, M. Ballesteros, M.J. Negro, Pretreatment technologies for an efficient bioethanol production process based on enzymatic hydrolysis: a review, Bioresour. Technol. 101 (2010) 4851-4861.

[38] M.A. Mandegari, S. Farzad, J.F. Görgens, Process design, flowsheeting, and simulation of bioethanol production from lignocelluloses, Biofuels Prod. Futur. Perspect. (2016) 255.

[39] D. Kim, Physico-chemical conversion of lignocellulose: Inhibitor effects and detoxification strategies: A mini review, Molecules. 23 (2018) 309.

[40] Z. Lin, H. Huang, H. Zhang, L. Zhang, L. Yan, J. Chen, Ball milling pretreatment of corn stover for enhancing the efficiency of enzymatic hydrolysis, Appl. Biochem. Biotechnol. 162 (2010) 1872-1880.

[41] A. Nutt, Hydrolytic and oxidative mechanisms involved in cellulose degradation, (2006).

[42] Y.E. Sun, Enzymatic hydrolysis of rye straw and Bermudagrass for ethanol production, (2002).

[43] Y.-H.P. Zhang, M.E. Himmel, J.R. Mielenz, Outlook for cellulase improvement: screening and selection strategies, Biotechnol. Adv. 24 (2006) 452-481.

[44] O.O. Oyekola, The enzymology of sludge solubilisation under biosulphidogenic conditions: Isolation, characterisation and partial purification of endoglucanases, (2003).

[45] A. V Gusakov, T.N. Salanovich, A.I. Antonov, B.B. Ustinov, O.N. Okunev, R. Burlingame, M. Emalfarb, M. Baez, A.P. Sinitsyn, Design of highly efficient cellulase mixtures for enzymatic hydrolysis of cellulose, Biotechnol. Bioeng. 97 (2007) 1028-1038.

[46] B.B. Hallac, A.J. Ragauskas, Analyzing cellulose degree of polymerization and its relevancy to cellulosic ethanol, Biofuels, Bioprod. Biorefining. 5 (2011) 215-225. 